\title{
¿HACIA UNA REGIÓN TURÍSTICA Y RESIDENCIAL? MURCIA, RESORT DE EUROPA
}

\author{
Marie François \\ ESO - Caen, UMR CNRS 6590. TELEMME, UMR CNRS 6570. Universidad de Caen - Basse Normandie
}

\section{RESUMEN}

El proceso de urbanización en España durante la última década del siglo XX ha sido muy intenso. Los años noventa se caracterizaron por una artificialización ${ }^{1}$ sin precedentes del territorio. Este proceso que sigue en esta primera década del tercer milenio se debe, en gran parte, al turismo que se desarrolla prioritariamente en el litoral. Sin embargo, cada vez más tierras del interior español se urbanizan y se especializan en el turismo. Esta urbanización turística, a menudo vinculada con la especulación o incluso con la corrupción, tiene implicaciones medioambientales y sociales que son el origen de conflictos. Por eso, se multiplican las plataformas ciudadanas que se preguntan sobre el modelo de desarrollo actual. En este contexto, en Murcia es donde el proceso es comparativamente más importante. El Gobierno de esta región tiene la clara voluntad de orientar su desarrollo económico y social hacia el turismo con los resorts (complejos turístico-residenciales basados en el modelo de las gated communities) como elemento fundamental.

Palabras clave: Región de Murcia, urbanización, complejos turístico-residenciales, medio ambiente, implicaciones sociales.

\section{RÉSUMÉ}

En Espagne, le processus d'urbanisation pendant la dernière décennie du XXème siècle a été explosif. Les années quatre-vingt-dix ont été caractérisées par une

1 La artificialización puede ser definida como el proceso de difusión de las zonas urbanas e industriales y de infraestructuras de transporte. Para los organismos oficiales, la superficie artificial incluye cuatro sub-grupos: las zonas urbanas, las zonas industriales, comerciales y de transporte, las zonas de extracción minera y las zonas verdes artificiales no agrícolas. 
artificialisation ${ }^{2}$ du sol sans précédent. Ce processus qui continue durant la première décennie du troisième millénaire est lié, en grande partie, au tourisme qui s'est développé principalement sur le littoral. Toutefois, de plus en plus de terres de l'intérieur espagnol se sont urbanisées et se sont spécialisées dans le tourisme. Cette urbanisation touristique, souvent liée la spéculation ou même à la corruption, a des implications environnementales et sociales à l'origine de conflits. C'est pourquoi, se multiplient des plates-formes citoyennes qui s'interrogent sur le modèle de développement actuel. Dans ce contexte, c'est dans la région de Murcie que le processus est comparativement le plus important. Le Gouvernement de cette région a la claire volonté d'orienter son développement économique et social vers le tourisme avec les resorts (complexes touristico-résidentiels basés sur le modèle des gated communities) comme élément fondamental.

Mots clés: Région de Murcie, urbanisation, complexes touristico-résidentiels, environnement, implications sociales.

\section{INTRODUCCIÓN}

En España los años noventa se caracterizaron por una artificialización sin precedentes del suelo. Este proceso, que prosigue en esta primera década del segundo milenio esta vinculado, en gran parte, al turismo que se desarrolla prioritariamente en el litoral. Sin embargo, cada vez más tierras del interior español se urbanizan y se especializan en el turismo. Se asiste a una urbanización del espacio rural con impactos sobre las poblaciones, el medio ambiente y los recursos hídricos.

En Murcia es donde el proceso es, comparativamente con el resto de España, más importante. La Región de Murcia basó su economía en el potencial de su espacio rural y su clima, valorizado por el riego. Sin embargo, la Huerta tradicional desaparece en favor de la construcción inmobiliaria que se convierte en el sector más rentable de la región. El proceso urbanístico de la Región de Murcia, que le vale hoy el nombre de Huerta inmobiliaria, está en gran parte vinculado al desarrollo del sector turístico. El turismo se convierte en el eje económico motor de la región. Siguiendo el modelo de las Gated Communities los grandes complejos hoteleros y residenciales cerrados, los resorts, se propagan en todo el territorio. Se convierten en el nuevo emblema de la región, tanto que se podría calificar Murcia de resort de Europa.

2 Lartificialisation peut être définie comme le processus de diffusion des zones urbaines et industrielles et des infrastructures de transport. Pour les organismes officiels, la superficie artificielle comprend quatre sous-ensembles : les zones urbaines, les zones industrielles, commerciales et de transports, les zones d'extraction minière et les zones vertes artificielles non agricoles. 


\section{LA URBANIZACIÓN EN ESPAÑA (1990-2007)}

Durante los años 90 y principios del siglo XXI, el proceso de artificialización fue desorbitado. Se asiste a una urbanización sin precedentes y a la construcción de espacios urbanos difusos, contrariamente al modelo tradicional de la ciudad mediterránea, concentrada y compacta. El consumo creciente del suelo, sin un aumento paralelo de la población, la descentralización progresiva del sector terciario, la peri-urbanización residencial de baja densidad y viviendas individuales son las características de la constitución de espacios urbanos difusos.

\section{La artificialización del suelo}

La superficie artificial aumentó en 30\% entre 1987 y 2000 (mapa 1), con provincias que sobrepasan el 40\% de aumento como las Baleares, Toledo, Navarra, Granada, Madrid, Cuenca, Castellón e incluso el 60\% como Murcia, Alicante y Ourense. Entre 2001 y 2007 se construyeron 3.455.525 viviendas en España. El arco mediterráneo, de la provincia de Girona a la de Málaga, representa un $40 \%$ del total. Al añadir Madrid, estas once provincias concentran la mitad de las viviendas construidas durante este periodo (mapa 2).

Mapa 1. Crecimiento de la superficie artificial por provincias entre 1987 y 2000

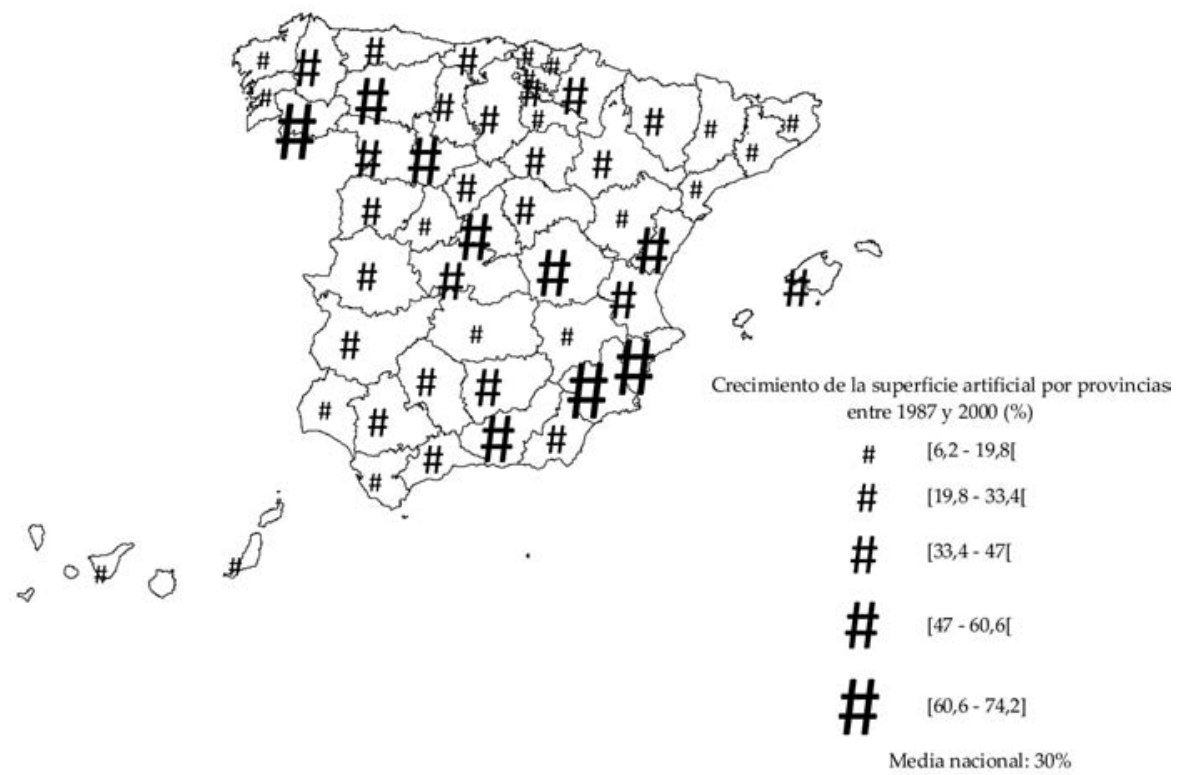

Marie François, ESO-Caen, TELEMME, 2011

Fuente: Observatorio de la Sostenibilidad en España, 2006 y Atlas del Ministerio de Vivienda 
Mapa 2. La construcción de viviendas en España entre 2001 y 2007

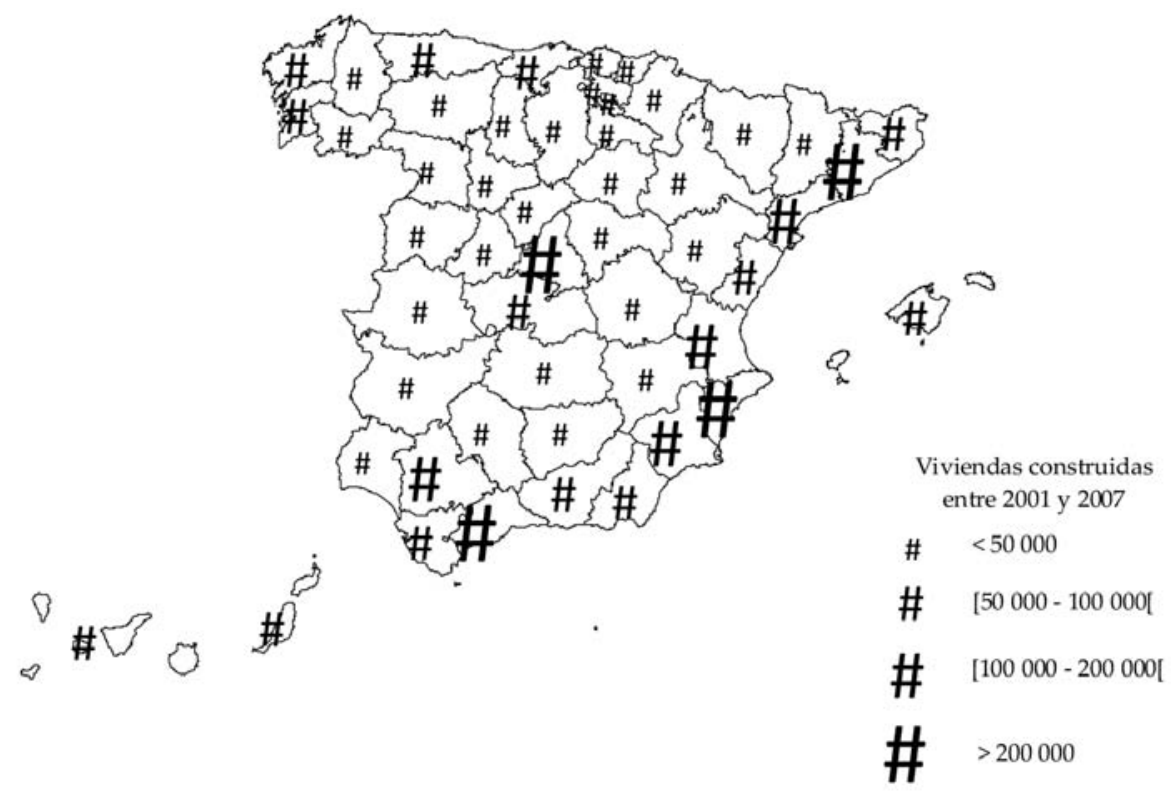

Total España: 3.455 .525

Marie François, ESO-Caen, TELEMME, 2011

Fuente: Burriel de Orueta E, 2008 y Ministerio de Vivienda

Sin embargo, esta artificialización y esta urbanización no se realizan al mismo tiempo que una explosión de la población. Durante el periodo 1991-2001, el número de viviendas en España aumentó un 21,6\%, mientras que la población sólo aumentó un 4,6\%. Por ejemplo, en Andalucía, las viviendas aumentaron un 24,4\% y la población el 5,3\%. En Castilla-La Mancha, las proporciones siguen siendo sensiblemente las mismas con 20,3\% y 5,3\%. Otras comunidades autónomas perdieron incluso habitantes, como CastillaLeón, Asturias y Extremadura (Instituto Nacional de Estadísticas, Censos 1991 y 2001).

Una de las razones por las cuales la curva de la población no sigue la de las viviendas es la proporción importante de residencias secundarias. En 2001, las residencias secundarias representan un 16\% de las viviendas en España (3.359.317 viviendas). Las regiones mediterráneas representan cerca del 43\% del total español, con una preponderancia en las provincias de Alicante, Valencia, Málaga y Barcelona (mapa 3). 
Mapa 3. Las residencias secundarias en España en 2001

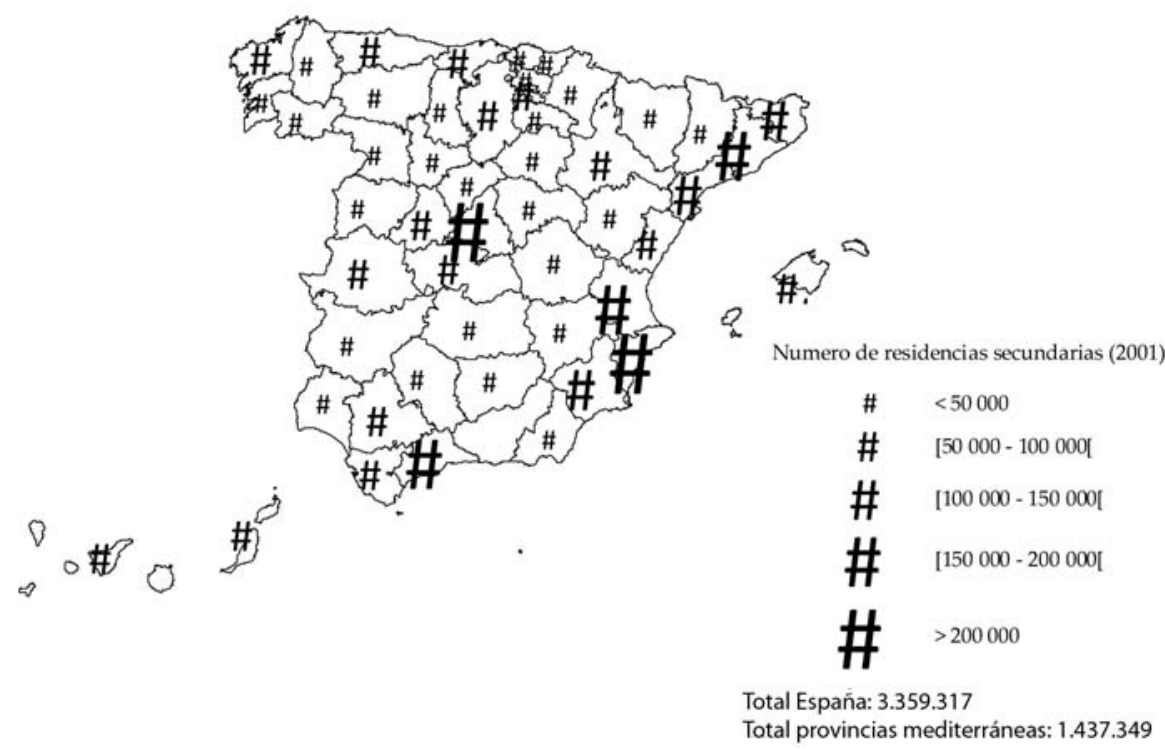

Marie François, ESO-Caen, TELEMME, 2011

Fuente: Instituto Nacional de Estadísticas, Censo 2001

Desde el principio del siglo XXI, se asiste, pues, en España a una intensificación del proceso de urbanización. Comparativamente al periodo 1987-2000, el ritmo fue mucho más constante entre 2001 y 2007. En efecto, mientras que entre 1987 y 2000 se urbanizaron 80.172 hectáreas en España, equivalente a una media de 6.167 hectáreas al año, entre 2001 y 2007 se transformaron 69.111 hectáreas, o sea, una media de más de 11.500 hectáreas al año. En términos absolutos, las Comunidades autónomas cuyas superficies fueron las más urbanizadas durante el periodo 2001-2007 son Andalucía (14.676 hectáreas), Cataluña (10.018 hectáreas), la Comunitat Valenciana (9.578 hectáreas) y la Comunidad de Madrid (7.169 hectáreas).

\section{El turismo: elemento fundamental del proceso urbanizador}

El sector turístico es el elemento fundamental del proceso urbanizador. Eso dio lugar a la creación de aglomeraciones urbanas litorales como Benidorm y Torrevieja, en la provincia de Alicante, Marbella y Mijas en la de Málaga y Roquetas del Mar en la provincia de Almería. El ejemplo más conocido es el de Benidorm, en la Comunitat Valenciana, símbolo del turismo de masas, con sus hoteles y sus 
edificios gigantescos que bordean la playa, un pueblo de apenas 3.000 habitantes en 1950 que sobrepasa los 50.000 habitantes en 2001.

En los años noventa, el turismo, además de consolidar el modelo «sol y playa», toma una nueva forma y se diversifica. Se desarrollan grandes complejos hoteleros y residenciales temáticos como Marina d'Or, en Oropesa del Mar, en la provincia de Castellón. El turismo residencial se desarrolla y el modelo hasta ahora vertical pasa al horizontal, imitando el modelo anglosajón de la ciudad dispersa, frente a la ciudad compacta mediterránea (Fundación Alternativas, 2007: 98).

Durante la última década del siglo XX y la primera del siglo XXI, las regiones mediterráneas españolas concentran población y artificialización del suelo. De este aumento del turismo resulta una mayor concentración de la población. Mientras que en 2003 la media nacional era de 84,4 hab/ $\mathrm{km}^{2}$, la de las regiones mediterráneas era de 186,6. Algunas provincias superaban esta cifra, como Barcelona $\left(653,8 \mathrm{hab} / \mathrm{km}^{2}\right)$, Alicante $\left(280,6 \mathrm{hab} / \mathrm{km}^{2}\right)$, Valencia $\left(214,7 \mathrm{hab} / \mathrm{km}^{2}\right)$ o Málaga $\left(188,1 \mathrm{hab} / \mathrm{km}^{2}\right)$. Pero, más que la población, es la artificialización del suelo lo que caracteriza las regiones mediterráneas. Algunos porcentajes de artificialización fueron superiores al 50\%, en particular en la Comunitat Valenciana $(52,1 \%)$ y en la Región de Murcia (62\%).

El aumento de la superficie artificial procede, sobre todo, del uso creciente de la franja litoral. La zona urbanizada que se extiende de Girona al estrecho de Gibraltar está, en gran parte, vinculada a la multiplicación de las infraestructuras turísticas y residenciales. Al final de la década 1990-2000, un 79\% de la capacidad de alojamientos se concentran en el litoral (Fundación Alternativas, 2007: 102). La saturación de la primera banda de costa $(0-1 \mathrm{~km})$ y la voluntad por diversificar el sector turístico y residencial son los dos factores del proceso urbano. La artificialización de la banda costera 0-10 km aumentó más de 57.000 hectáreas entre 1990 y 2000, lo que representa un crecimiento de más de 20\% en diez años.

Las provincias que conocen los aumentos más fuertes son las de Alicante (52,5\%), Castellón (43,5\%), las Islas Baleares (38,5\%), Huelva (31\%), Valencia $(29,8 \%)$ y Murcia $(28,6 \%)$. Las urbanizaciones extensivas son responsables del tercio de este aumento de la superficie artificial, con un crecimiento de más de 18.000 hectáreas entre 1990 y 2000.

Durante los quince últimos años, el turismo residencial se desarrolló en España con la creación de macroresidencias de varios millares de viviendas. Desde el principio del siglo XXI, este proceso se propaga hacia el interior del país. El «nuevo turismo residencial» es el gran responsable de este fenómeno calificado de urbanización del campo, donde el producto estrella es el campo de golf. Se ve aparecer un modelo «sol-golf» en las zonas interiores. 


\section{EL USO RESIDENCIAL, NUEVO EJE MOTOR DE DESARROLLO DE LA REGIÓN DE MURCIA}

Tradicionalmente, el turismo en la Región de Murcia se basaba en el aprovechamiento del sol y la playa, en particular en la zona de La Manga del Mar Menor. Esta zona fue transformada completamente por la urbanización y la construcción de infraestructuras turísticas en los años 70 del siglo XX.

\section{Algunas cifras}

En 2007, sobre 228 hoteles y pensiones en la Región de Murcia, más de la mitad se localiza en el litoral (24 en Cartagena, 18 en Mazarrón, 16 en San Javier, 15 en Águilas, 12 en San Pedro del Pinatar y 12 en la zona La Manga) y en Murcia capital (39). Estos hoteles y pensiones contabilizan 19.571 plazas, cuyas tres cuartas partes se sitúan en la zona de La Manga (4.731), en Murcia capital (4.009), en Cartagena (2.661), en San Pedro del Pinatar (1.168) y en Águilas (916).

Por lo que se refiere a los apartamentos turísticos, la localización es relativamente idéntica. En 2007, la Región de Murcia cuenta con 2.039 apartamentos turísticos, la mitad de los cuales se localiza en la zona La Manga (1.032). En términos de plazas, la situación es similar. Sobre un total de 8.673 plazas, más del 60\% se localiza en la zona de La Manga (4.693) y Mazarrón (1.161).

Entre 2002 y 2007, estos apartamentos turísticos son los que conocen el aumento más fuerte: 8.224 en 2002, 8.673 en 2007. A diferencia de los años anteriores, este tipo de alojamiento turístico se desarrolla en el interior de la región, relacionado, en parte, con el auge del turismo rural. Los municipios de Archena, Caravaca de la Cruz, Moratalla y de Villanueva del Río Segura son ejemplos característicos de estos cambios turísticos y residenciales. Archena pasa de 16 apartamentos (61 plazas) en 2002 a 48 (121 plazas) en 2007, y Caravaca de la Cruz, Moratalla y Villanueva del Río Segura, que no ofrecían este tipo de alojamiento en 2002, cuentan, respectivamente, con 22, 8 y 4.

La Ley del Turismo de 1997 de la Región de Murcia sirvió de base para el lanzamiento del desarrollo turístico regional. Pero es el Plan Estratégico de desarrollo de la Región de Murcia 2000-2006 (Consejería de Economía y Hacienda de Región de Murcia, 2000) el que hace del turismo uno de los pilares fundamentales para el desarrollo de la región. Entre sus líneas estratégicas, se indica que es necesario, en la zona de La Manga, favorecer un turismo de calidad y no limitado a épocas determinadas; favorecer el turismo del interior y desarrollar el potencial turístico del litoral meridional de la costa Cartagena-Mazarrón-Águilas. El Plan Director del Turismo de la Región de Murcia 2006-2012 (Consejería de Turismo, Comercio y Consumo, 2006) reitera esta voluntad de hacer del turismo un eje motor del desarrollo regional. 
Un punto fundamental en el desarrollo turístico es el deseo de diversificar la oferta y de extenderlo a toda la región. Para ello, se establecen planes de dinamización turística como los de la Sierra Espuña, al oeste de Murcia, de El Valle de Ricote, al noreste, Caravaca de la Cruz, al noroeste, Águilas y Mazarrón, al suroeste. Los complejos hoteleros y residenciales con piscinas y campos de golf, los resorts, constituyen el elemento central de dinamización. El Gobierno murciano, dirigido por el Partido Popular, tiene la clara voluntad de desarrollar su economía sobre un modelo turístico basado en el resort. El Departamento regional del Turismo defiende todas las acciones que siguen esta orientación. El propio Presidente de la región, Ramón Luis Valcárcel, participa activamente en los procesos de promoción de estos nuevos destinos ante clientes potenciales. Así, se desplazó en persona a Londres en mayo de 2006 para promover la imagen de Murcia, recoger a la clientela e incitar a los promotores a invertir en la región. Se trata de una verdadera «misión comercial» ${ }^{3}$. El objetivo consistía en hacer de Murcia un «auténtico objeto de deseo y escenario de captación de inversiones a nivel mundial» ${ }^{4}$.

En este desarrollo turístico-residencial, el campo de golf se convierte en el elemento de venta, el «plus» que permite atraer turistas.

Así el sector turístico residencial ha encontrado en el campo de golf un elemento que otorga un nuevo valor añadido a su producto inmobiliario cuando se ve obligado a alejarse de la primera línea de costa, sustituyendo el azul del mar por el verde del green (Aledo Tur, 2008: 105).

\section{El ejemplo de Marina de Cope}

El Gobierno regional quiere hacer de Murcia la región turística española o incluso europea por excelencia. Diversificar la oferta y, sobre todo, hacer que el sector turístico funcione a lo largo del año son dos de los objetivos del Gobierno murciano.

Considerando las tendencias de la demanda actual y futura, las carencias de la actual oferta complementaria del litoral de la Región de Murcia y las oportunidades que este espacio brinda se propone basar la actuación en tres pilares: golf, marina interior y deportes al aire libre. El modelo de desarrollo urbanístico que se planteará para este nuevo espacio se encuentra a mitad de camino entre la fórmula del Resort autónomo y el espacio residencial turístico abierto (Consejería de Turismo, Comercio y Consumo, 2004: 57-58).

3 La Verdad de Murcia, 3 de mayo de 2006, Valcárcel presenta en Londres el «turismo de baja densidad como gran ventaja competitiva frente a otras comunidades.

4 El Faro. Valcárcel quiere convertir la Región en un destino familiar en el Reino Unido. 3 de mayo de 2006 
En este contexto, el proyecto Marina de Cope (mapa 4) es el proyecto clave del Gobierno regional.

Marina de Cope es un gran proyecto del Gobierno de la Consejería de Turismo, que se consideró hace años absolutamente necesario para que la Región de Murcia tuviera una oferta turística de primer nivel en todo el Mediterráneo (...). Es el gran proyecto de futuro de la región en materia turística (...). Es el gran proyecto que podrá competir con los grandes que se están construyendo en toda la cuenca mediterránea (El Faro de Cartagena, 12 julio 2007, José Pablo Ruiz Abellán, «Con Marina de Cope podremos competir en oferta con todo el Mediterráneo»).

Marina de Cope, acción estratégica de las Directivas y del Plan de Ordenación Territorial del litoral de la Región de Murcia de 2004, obtiene el estatuto de Acción de Interés Regional5 (AIR) por la Resolución del 28 de julio de 2004. Situada sobre los municipios de Lorca y Águilas (sector de agricultura de regadíos esencialmente de lechugas y tomates), este AIR ilustra la amplitud y el dinamismo del proceso de urbanización turística. Marina de Cope se convierte en la «capital inmobiliaria de la Región de Murcia» ${ }^{6}$.

De una superficie de 2.116 hectáreas, Marina de Cope pretende ser el mayor complejo urbano-turístico de Europa, compuesto de cinco campos de golf y de una marina interior de una superficie de agua de 25 hectáreas, que pueden acoger 1.500 embarcaciones. La oferta turística global será de 23.000 plazas hoteleras y la zona residencial implicará 11.000 alojamientos. Así pues, este complejo podrá reunir a una población total de 60.000 habitantes. La localización del proyecto hace necesario el desarrollo de infraestructuras de transporte, segundo factor de artificialización de los suelos. El acceso al complejo Marina de Cope se hará gracias a una conexión, en su parte noroeste, a la autopista Cartagena-Vera. Entrada en funcionamiento en marzo de 2007, esta autopista de $114 \mathrm{~km}$ es un verdadero «eje para el turismo» ${ }^{7}$.

\section{LOS COMPLEJOS TURÍSTICO-RESIDENCIALES CERRADOS EN LA REGIÓN DE MURCIA}

En la Región de Murcia, el Resort se convirtió en una «auténtica epidemia». Destinado esencialmente a las poblaciones extranjeras, mayoritariamente británicas, el Resort es un nuevo modelo turístico y residencial que recuerda el modelo de las gated communities.

5 Las Actuaciones de Interés Regional están reguladas por la Ley del Suelo de 2001 de la Comunidad de Murcia.

6 El Mundo. «Marina de Cope, capital actividad inmobiliaria de Murcia». 6 de mayo de 2005.

7 Revista el Economía. «La autopista Cartagena-Vera, un eje para el turismo». 6 de agosto de 2006. 
Mapa 4. Localización del proyecto Marina de Cope

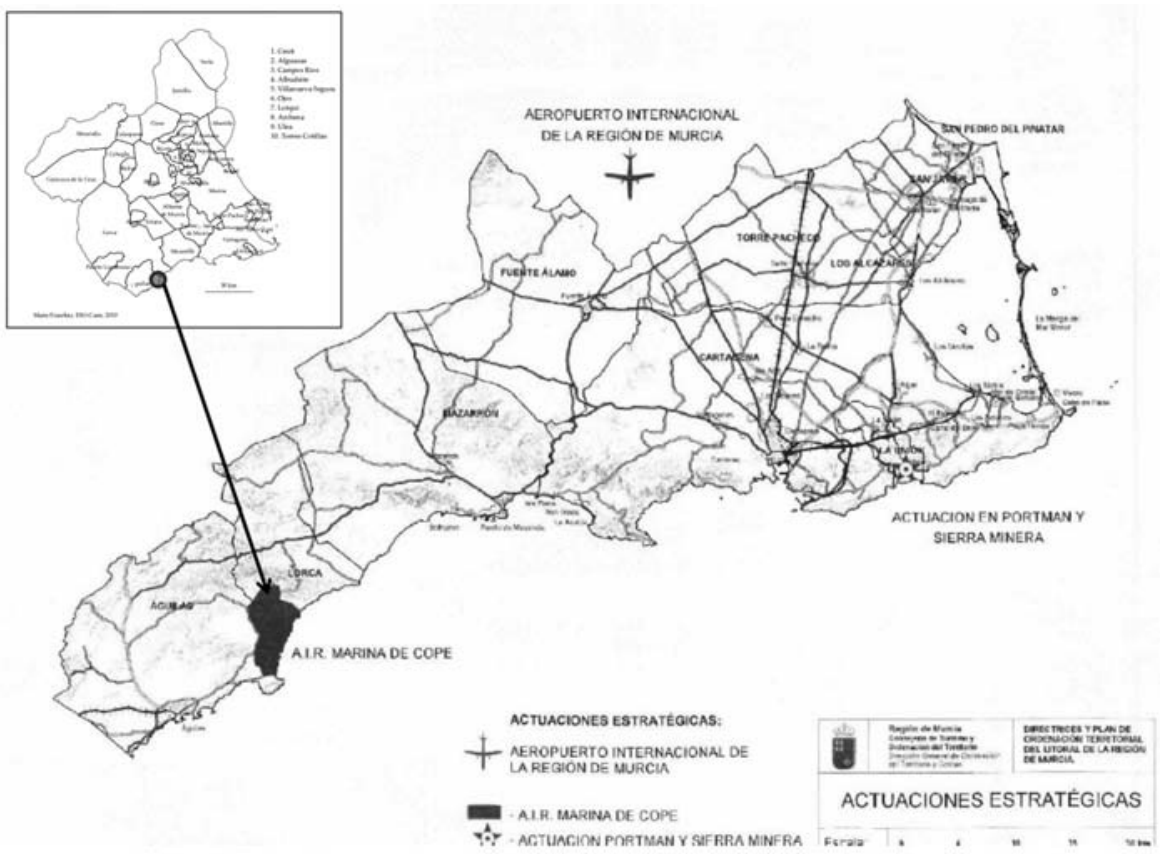

Fuente: Consejería de Turismo y Ordenación del Territorio Región de Murcia, 2004.

\section{Características de estos Resorts}

Estos complejos hoteleros y residenciales, con piscinas y campos de golf que constituyen el elemento central, están dotados con numerosas infraestructuras como centros comerciales, centros de salud o incluso colegios, etc. (Figura 1 y 2).

El Departamento de Turismo defiende todas las acciones en proyecto en la región y se basa en el derecho al desarrollo. Un artículo de opinión de José Pablo Ruiz Abellán, Consejero del Turismo de la Región de Murcia de 1995 hasta 2008, aparecido en el diario La Verdad de Murcia, expresa claramente esta orientación económica y las ventajas que la región alega para orientarse hacia un turismo basado en el Resort:

La Región de Murcia (...) desea incorporarse a ese tipo de turismo moderno y de calidad que está emergiendo con fuerza, el de los Resorts, en los que el turista busca la tranquilidad de una residencia propia o de un hotel, que está ubicado en un entorno agradable en el que se ofrezcan unos servicios de calidad y en el que se pueda practicar ese deporte tan relajante que es el golf. La realidad es que la Región de Murcia reúne unas inmejorables condiciones para ello (La Verdad de Murcia, 24 julio 2005, «Turismo sin complejos»). 
Figura 1. El campo de golf, elemento central del Resort (La Torre Golf)

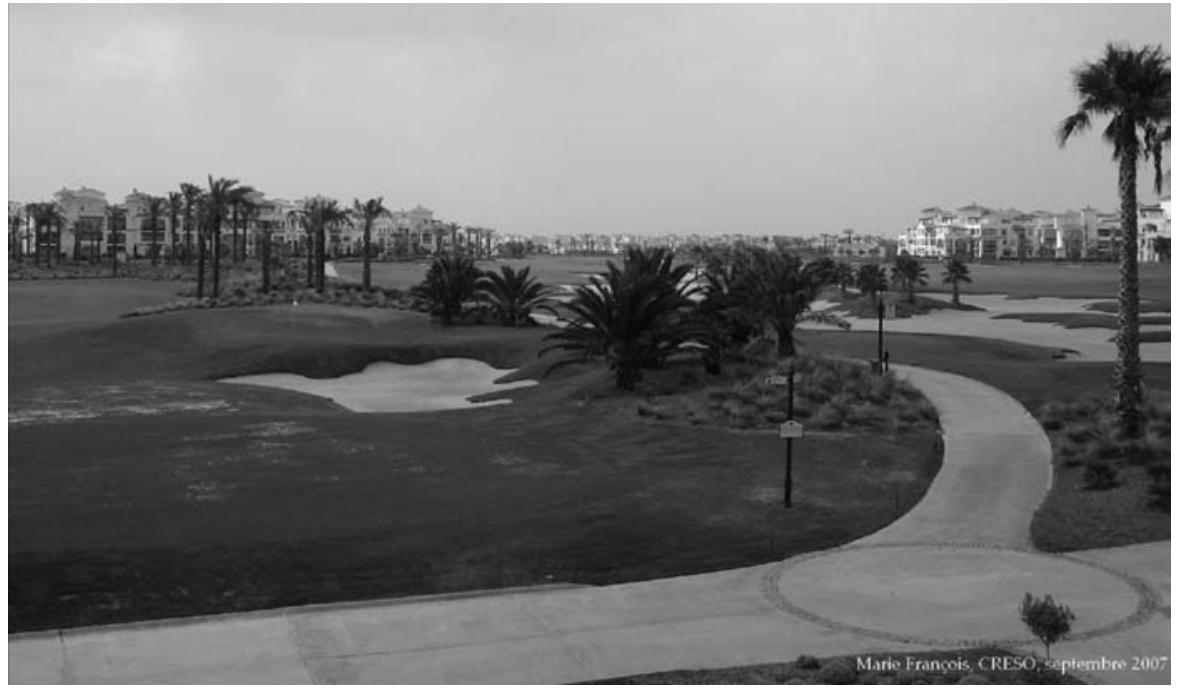

Es en torno del campo de golf que se construye el Resort

Figura 2. La piscina: otro elemento atractivo del Resort

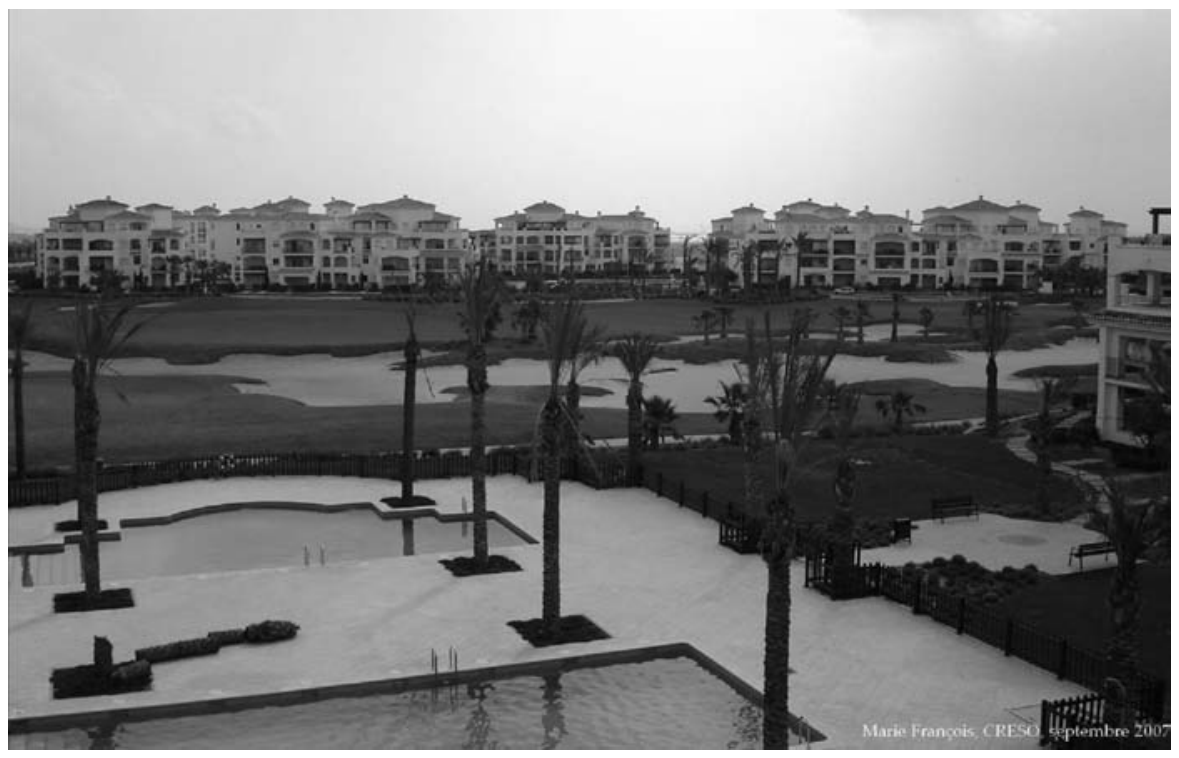

La piscina es el segundo elemento del Resort. Se localiza al lado del campo de golf 


\section{La empresa Polaris World}

En este nuevo modelo de turismo, la Región de Murcia cuenta con la presencia de una empresa inmobiliaria y turística: Polaris World. Creada en 2001 con el apoyo financiero de los bancos Cajamurcia y Caja de Ahorros del Mediterráneo, esta empresa murciana es el «nuevo paraíso del turismo residencial ${ }^{8}$. Polaris World cuenta en su activo siete Resorts, con el golf como elemento central. Todos los complejos de Polaris ocupan una superficie de alrededor de 1.600 hectáreas y suman más de 15.000 viviendas. Estos complejos se desarrollan esencialmente por el interior de la región, pero siempre en un radio de quince minutos de distancia de la costa y en torno a las pequeñas ciudades, transformando así el espacio agrícola tradicional (Figura 3).

Figura 3. Localización de los Resorts de Polaris

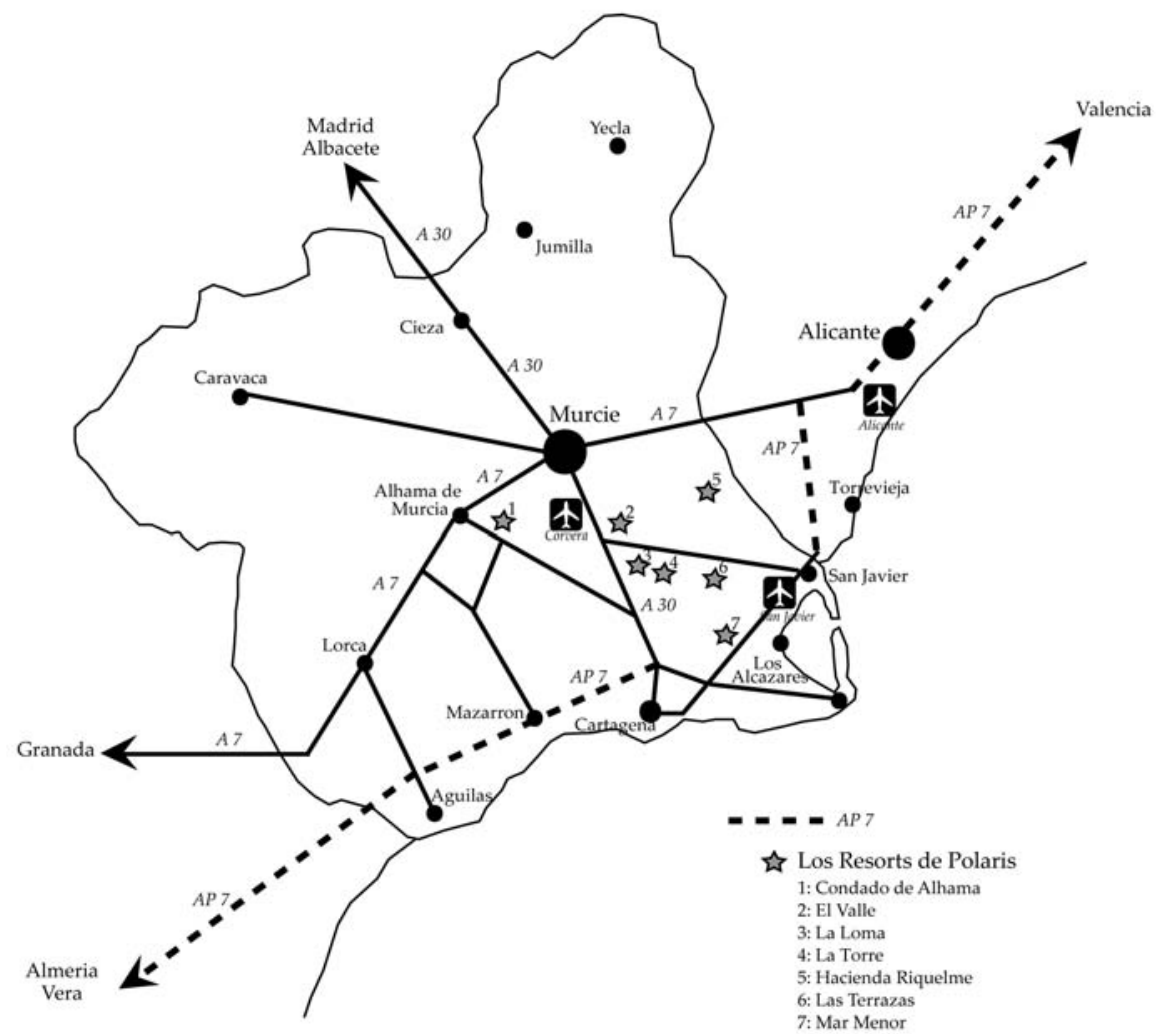

Marie François, ESO-Caen, TELEMME, 2011

Fuente: Página web de Polaris World [febrero de 2009]

8 La Razón. 12 de diciembre de 2003. «Polaris World y "nuevo paraíso" de turismo residencial». 
La costa propiamente dicha no es ahora el ámbito exclusivo y central de ubicación de sus instalaciones. Conforme se ha ido masificando el litoral, se han ido construyendo nuevos centros residenciales en ámbitos rurales prelitorales (García Marín, 2008: 282).

La accesibilidad es un segundo factor de localización. Numerosos son los Resorts situados cerca de las autopistas que conectan a Murcia con la Comunitat Valenciana, Andalucía o la Comunidad Autónoma de Madrid.

El último resort de Polaris reúne todas las características esenciales de los resorts. Condado de Alhama, situado en una zona agrícola de vides y naranjos, bordea la autopista AP7, que recorre todo el litoral mediterráneo y se sitúa a diez minutos de las playas de Mazarrón. «Un lugar que reúne condiciones increíbles para la práctica del golf» (folleto publicitario de Polaris World sobre Condado de Alhama).

Pensamos en el golf como elemento paisajístico y creamos «El gran pulmón verde» de Condado de Alhama. $2500000 \mathrm{~m}^{2}$ de green junto con $800000 \mathrm{~m}^{2}$ de zonas verdes (la superficie equivalente a 500 campos de fútbol) distribuidas por todo el Condado conforman esta algazar de la naturaleza, donde se alzan miles de notas ticando una única melodía: la del agua en sus numerosos recorridos (folleto publicitario de Polaris World sobre Condado de Alhama, Polaris World, sin fecha).

Además del golf, el agua es el segundo elemento de comercialización:

Pensamos en el agua como elemento necesario para la vida y lo incorporamos como pilar fundamental de nuestro proyecto. El gran lago envuelve al Oasis, el corazón de Condado de Alhama (folleto publicitario de Polaris World sobre Condado de Alhama, Polaris World, sin fecha).

Condado de Alhama agruparía seis resorts sobre una superficie total de 900 hectáreas. Se compondrá de tres campos de golf de una superficie total de 250 hectáreas, uno de los cuales de 96 hectáreas. Cada uno de los resorts tendrá un Town Center con centro comercial, farmacia, restaurantes, bares, piscina, etc. El Oasis, de $75.000 \mathrm{~m}^{2}$, será el centro neurálgico de todo el complejo:

El oasis ha sido diseñado como isla en el centro de gran lago; una medina rodeada de agua y palmeras (...). Se trata de una pequeña isla en la que se alza el Palacio, una zona que propone el culto al baño con los mejores medios para disfrutar de todo lo que tenga que ver con el agua: jacuzzis, saunas y piscinas (folleto publicitario de Polaris World sobre Condado de Alhama, Polaris World, sin fecha).

En una primera fase están previstas 2.500 viviendas y, a largo plazo, 12.000. Los precios varían de 89.000 a 1.406 .000 euros según el tipo de alojamiento (apartamento o vivienda unifamiliar), la superficie y la localización (más o menos cerca de los campos de golf). Condado de Alhama dispondrá también de un colegio británico, de un hospital y de un hotel cinco estrellas. 


\title{
UN DESARROLLO DESTRUCTIVO DEL MEDIO AMBIENTE Y LAS RELACIONES SOCIALES
}

\begin{abstract}
Allí, en mitad del desierto que se extiende por el sureste español surge ante la mirada atónita del conductor un sueño hecho de green y agua (...). El conductor reflexivo puede preguntarse ante la paradoja paisajística que se le aparece delante de sus ojos de dónde surge este sueño, cuáles son las fuerzas que lo crean y cuáles serán sus consecuencias si llegase a cumplirse. Este sueño es producto del Nuevo Turismo Residencial (Aledo Tur, 2008: 99).
\end{abstract}

Este nuevo turismo residencial, el de los resorts en particular, no puede analizarse bajo el simple, o incluso simplista, enfoque medioambiental, sino también, y quizás, sobre todo, desde el punto de vista de sus implicaciones sociales y económicas. Con este tema de los resorts, nos encontramos en el centro del debate en torno a nuestro modelo de desarrollo occidental: ¿es viable? ¿El crecimiento económico para quién? ¿Por qué? ¿Otro modelo es posible?, etc.

\section{Un modelo consumista}

El medio ambiente ha pagado el precio más caro del crecimiento socioeconómico rural basado en el desarrollo turístico-residencial, y es precisamente en este subsistema en el que se concentran los riesgos fundamentales para la viabilidad futura del desarrollo de la región pues, desde hace tiempo, se han venido produciendo daños irreparables (García Marín, 2008: 285).

El turismo residencial y sus grandes complejos tienen como corolarios el aumento del consumo de recursos medioambientales, como el suelo o el agua, y la transformación de los paisajes.

Sobre las 178 operaciones residencias asociadas con golf aprobadas o en curso de aprobación en julio de 2007 en el Levante, 69 se localizan en la Región de Murcia. Eso representa 29.880 hectáreas y 326.934 viviendas. Con una media de 2,2 personas por vivienda, estos complejos podrían acoger a 719.254 habitantes (Navarro Vera, Ortuño Padilla, 2008b).

Desde el punto de vista de los recursos hídricos, la consolidación de este modelo especializado en la urbanización turística tiende a generar un mayor consumo de agua. El consumo medio anual de un campo de golf por hectárea es de 8.000 $\mathrm{m}^{3} / a n ̃ o$; así, es superior a numerosos regadíos, y a grandes consumidores en agua, en la Región de Murcia, como la lechuga iceberg ( $\left.4.500 \mathrm{~m}^{3} / \mathrm{Ha} / \mathrm{año}\right)$, el albaricoque $\left(5.250 \mathrm{~m}^{3} / \mathrm{Ha} / \mathrm{año}\right)$ o los tomates bajo invernadero $\left(7.000 \mathrm{~m}^{3} / \mathrm{Ha} / \mathrm{año}\right)$.

Por otra parte, el modelo de desarrollo urbanístico de residencias asociadas con golf excede tres veces el consumo diario de las viviendas de una ciudad compacta tradicional, respectivamente, 1.200 litros/día/vivienda y 450 litros/día/ vivienda (Navarro Vera, Ortuño Padilla, 2008b). 
Los grandes complejos turístico-residenciales tienen también consecuencias sobre el cambio de uso del suelo y transforman los paisajes.

El proyecto del complejo Marina de Cope, hecho posible por la ley del suelo de 2001 de la Región de Murcia, recalifica 1.600 hectáreas del parque Regional Cabo Cope-Calnegre creado en 1992 (Ley 4/92 de Ordenación y Protección del territorio de Región de Murcia). Marina de Cope se encuentra en el centro de varias zonas protegidas como Lugares de Interés Comunitario y Zonas de Protección Especiales para las Aves.

En paralelo a estas recalificaciones, a finales de diciembre de 2008 y a principios de enero de 2009, los Plenos de los Ayuntamientos de Lorca y Águilas aprobaron, temporalmente, la modificación de su Plan General Municipal de Ordenación. El Pleno de Lorca aprobó el cambio de asignación de 700 hectáreas en suelo residencial $^{9}$, y el de Águilas el cambio de 1.400 hectáreas ${ }^{10}$. Las infraestructuras de transportes, vías de acceso a estos grandes complejos, son elementos esenciales de modificación de los paisajes, de cambios de uso del suelo e impactos medioambientales. El acceso al complejo Marina de Cope va a realizarse por una conexión con la reciente autopista AP7 Cartagena-Vera. A los impactos directos de esta autopista en los suelos y los ecosistemas se añaden efectos indirectos: la autopista se convierte en factor del proceso urbano-turístico. Las perspectivas de desarrollo creadas por el anuncio de su realización facilitaron la urbanización, la elaboración y la creación de grandes proyectos de infraestructuras turísticas sobre el litoral.

Además de Marina de Cope, otros proyectos jalonan este eje, que algunos califican de ruta de la especulación ${ }^{11}$, bajo una política completamente antagónica al desarrollo sostenible y a la gestión duradera del litoral ${ }^{12}$. Con los distintos proyectos urbano-turísticos, pequeñas ciudades de la provincia de Almería, como Cuevas, Vera, Mojácar o Pulpí (respectivamente, en 2005, 11.848 habitantes, 10.439 habitantes, 6.092 habitantes y 7.600 habitantes) van a transformarse en verdaderas aglomeraciones litorales, con una población que alcanzaría los 500.000 habitantes en Cuevas.

9 La Verdad de Murcia. 29 de diciembre de 2008. «El Ayuntamiento saca adelante el segundo trámite de Marina de Cope con la mayoría absoluta del PP».

${ }^{10}$ La Verdad de Murcia. 3 de enero de 2009. «El Pleno aprueba el uso residencial de 14 millones de metros de Marina de Cope».

${ }^{11}$ Jaime del Val, Presidente de Salvar Mojácar, El País 17/12/05.

12 Julia Martínez Fernández, 2002 <http://www.ecoportal.net/content/view/full/21465> [diciembre de 2002] 


\section{Privatización y homogeneización}

No obstante y a pesar de lo expuesto, conducir el debate ambiental sobre los efectos del modelo de urbanización con campo de golf hacia la discusión en torno a su mayor o menor consumo de recursos hídricos es un enfoque simplista (Aledo Tur, 2008:107). El turismo residencial ha provocado fuertes convulsiones culturales, ocasionando en algunos municipios la total desaparición de la cultura local y su sustitución por una nueva cultura turística, cosmopolita y global (Aledo Tur, 2008: 100). Sobre esta superficie sin matices y sin historia ya se puede levantar el sueño del promotor (Aledo Tur, A, 2008: 109).

Esta «moda» de los resorts, de los complejos del tout en un tiene también efectos, implicaciones sobre los modos de vida, la cultura y las relaciones sociales. Aparecen nuevas formas de apropiación y una mercantilización del espacio rural:

Los procesos de macrourbanización rural (countries clubs o resorts) vienen favorecidos por el desarrollo de los medios e infraestructuras de transporte y de comunicaciones, que han supuesto una ampliación del escenario de actuación del capitalismo sobre el medio rural (...). Estas nuevas urbanizaciones aisladas de los núcleos principales, exclusivas del uso residencial (...) evidencian el cambio y la segregación espacial y social (García Marín, 2008: 286-287).

Los resorts privatizan, aseguran y homogenizan. Para el resort, la demanda exterior es el factor más determinante. Algunos hablan de España como la «Gran Florida de Europa $»^{13}$. Dedicados esencialmente a poblaciones extranjeras europeas, en su mayoría británica, estos resorts rompen la cohesión social de la región, no tejen vínculos con las poblaciones locales. Los residentes viven en autarquía dentro de estos complejos que disponen casi de todos los servicios. ¿Por qué ir al exterior si tiene todo en el interior?

Una investigación sobre el turismo residencial (Huete Nieves et al, 2008), realizada con distintos protagonistas sociales (asociaciones de comerciantes, promotores inmobiliarios, partidos políticos, ciudadanos, etc.) por el Departamento de Sociología de la Universidad de Alicante, pone de relieve esta escasa o inexistente integración a la sociedad local:

Como se apuntaba antes, se critica sólo tímidamente el hecho de que los extranjeros suelan mantenerse aislados en sus urbanizaciones y establezcan sus propios negocios y lugares de encuentro sin esforzarse por aprender el español, a pesar de llevar muchos de ellos varios años establecidos o residiendo de forma casi permanente en España (Huete Nieves et al, 2008: 116).

\footnotetext{
${ }^{13}$ Fernández Durán, R., 2006.
} 
Estos complejos homogenizan el espacio y la sociedad. Todo está estandarizado y lineal: un resort es idéntico a otro (Figura 4), una vivienda es similar a otra, las calles son idénticas (Figura 5).

Figura 4. Vista aérea de los resorts

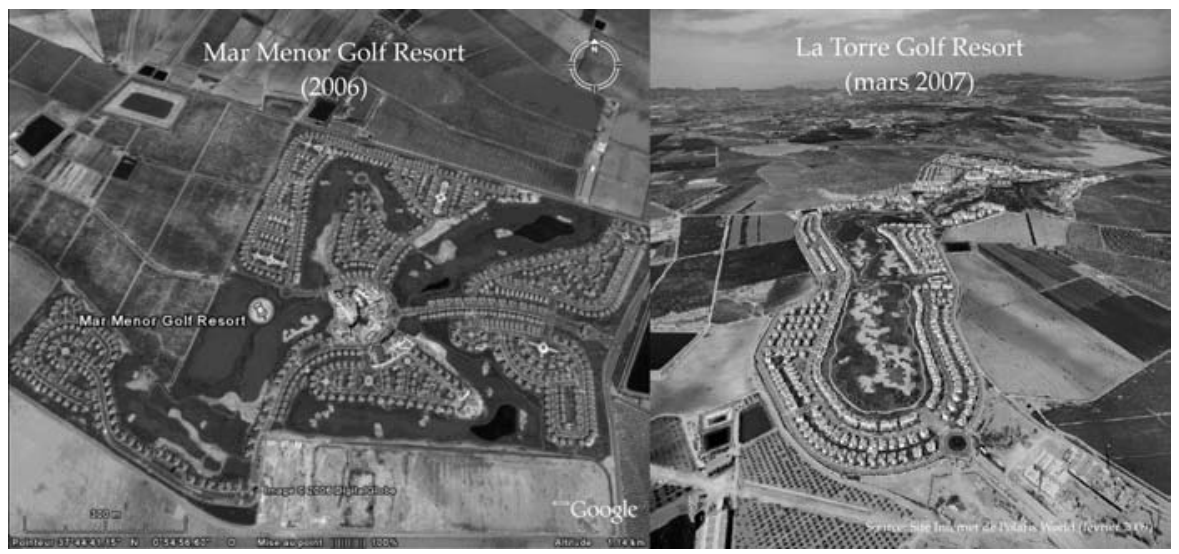

Fuente: Mar Menor Golf resort: googleearth (2006)

La Torre Golf Resort: Fuente: http://www.polarisworld.com/polarisworld/es/home [febrero de 2009]

Figura 5. La homogeneización del espacio La Torre Golf Resort

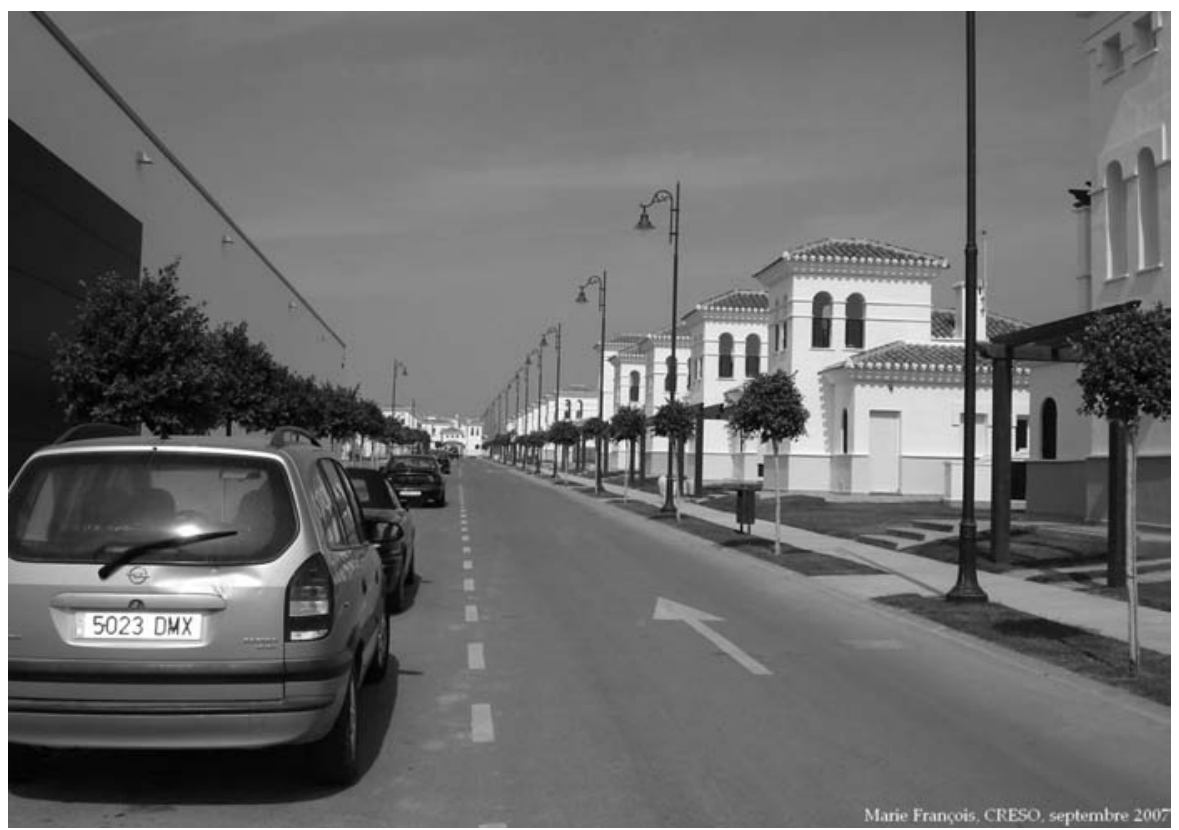

Investigaciones geográficas, $\mathrm{n}^{\circ} 52$, pp. 73 - 98 
La vida de un residente en el resort es idéntica a la de su vecino. En los resorts de Polaris se puede «vivir Polaris». Es, por otra parte, el lema de venta de esta empresa. Polaris pone todos sus esfuerzos para que los residentes puedan alimentarse, ocuparse, educarse, etc. in situ, en dos palabras: «Vivir Polaris», ofreciendo así, a los que lo quieren, la posibilidad de comenzar una nueva vida. Polaris World piensa en todo y gestiona todo (Figura 6).

Figura 6. Una vida gestionada por Polaris World

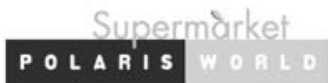

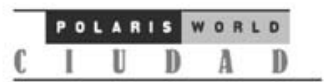

RENT A CAR

POLARIS WORLD
Senini

POLARIS WORLD

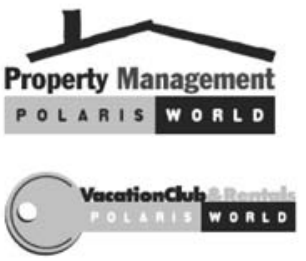

Garden Centre

POLARIS WORLD

Centro de Jardinería

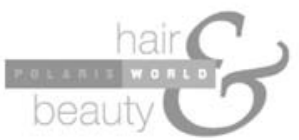

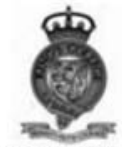

King's College n..........
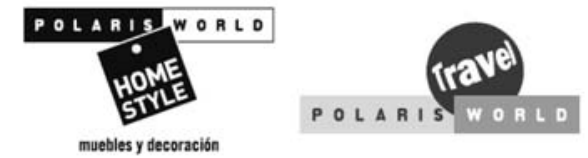

POLARIS WORLD

DESARROLLO

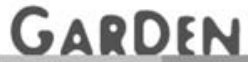

POLARIS WORLD

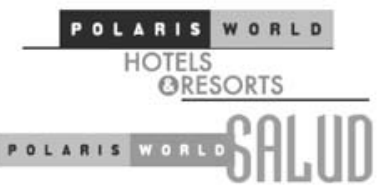

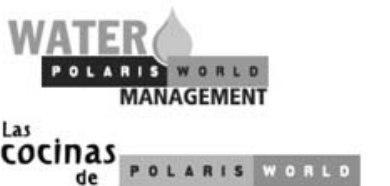

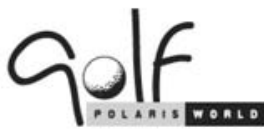

POLARIS WORLD T'ELECDII

Fuente: http://www.polarisworld.com/polarisworld/es/home [febrero de 2009]

Polaris no es sólo una inmobiliaria, es un concepto mucho más amplio. Intentamos prestarles todos los servicios a nuestros clientes, es un proyecto que se prolonga en el tiempo más allá de la actividad inmobiliaria inicial. Otros realizan una promoción y ahí terminan su negocio. Nosotros luego nos quedamos dentro de los complejos que construimos, dando todos los servicios de una ciudad (...). Nosotros hacemos urbanizaciones cerradas desde el punto de vista arquitectónico. Pero no sólo vendemos una casa, vendemos mucho más. Es como un hotel. La única diferencia es que en vez de alquilar una habitación se compra una vivienda. Luego damos todos los servicios: electricidad, fontanería, servicios médicos, supermercados, bares, restaurantes, enseñanza. Y todo gestionado por nosotros, porque creemos que es muy importante mantener los servicios en el futuro (Entrevista de Pedro García Meroño, Presidente de Polaris World, Revista la Economía de la Región de Murcia, noviembre de 2005). 
Una vez entrado en el mundo Polaris, es difícil salir. De la infancia a la jubilación, del supermercado a la salud, Polaris está aquí. ¿Quiere hacer compras? Tiene Polaris Supermarket. ¿Un problema de salud? Diríjase a Polaris Salud. ¿Escolarizar a sus niños? Inscríbalos en Polaris World International School Colegio Británico. ¿Arreglar su alojamiento? Polaris Home style podrá satisfacerle. ¿Rentabilizar su inversión? Polaris Rental le permite gestionar el alquiler de su alojamiento en su ausencia, etc., y, sobre todo, no se preocupe por problemas de agua en la región: Polaris World, desde 2006, empezó la construcción de una desalinizadora localizada en Mazarrón con el fin de abastecer a más de 250.000 personas. «Así quedan asegurados los recursos hídricos externos de forma indefinida con el objeto final de sostener la utopía occidental del crecimiento ilimitado» (Aledo Tur, 2008: 107).

Los resorts son espacios privados y exclusivos que solamente los miembros frecuentan. Con Polaris están tranquilos, entre ellos y con seguridad (Figura 7). La seguridad es un elemento publicitario y un argumento de venta de primer orden.

Figura 7. Encerramiento y seguridad (vista exterior del resort La Torre Golf)

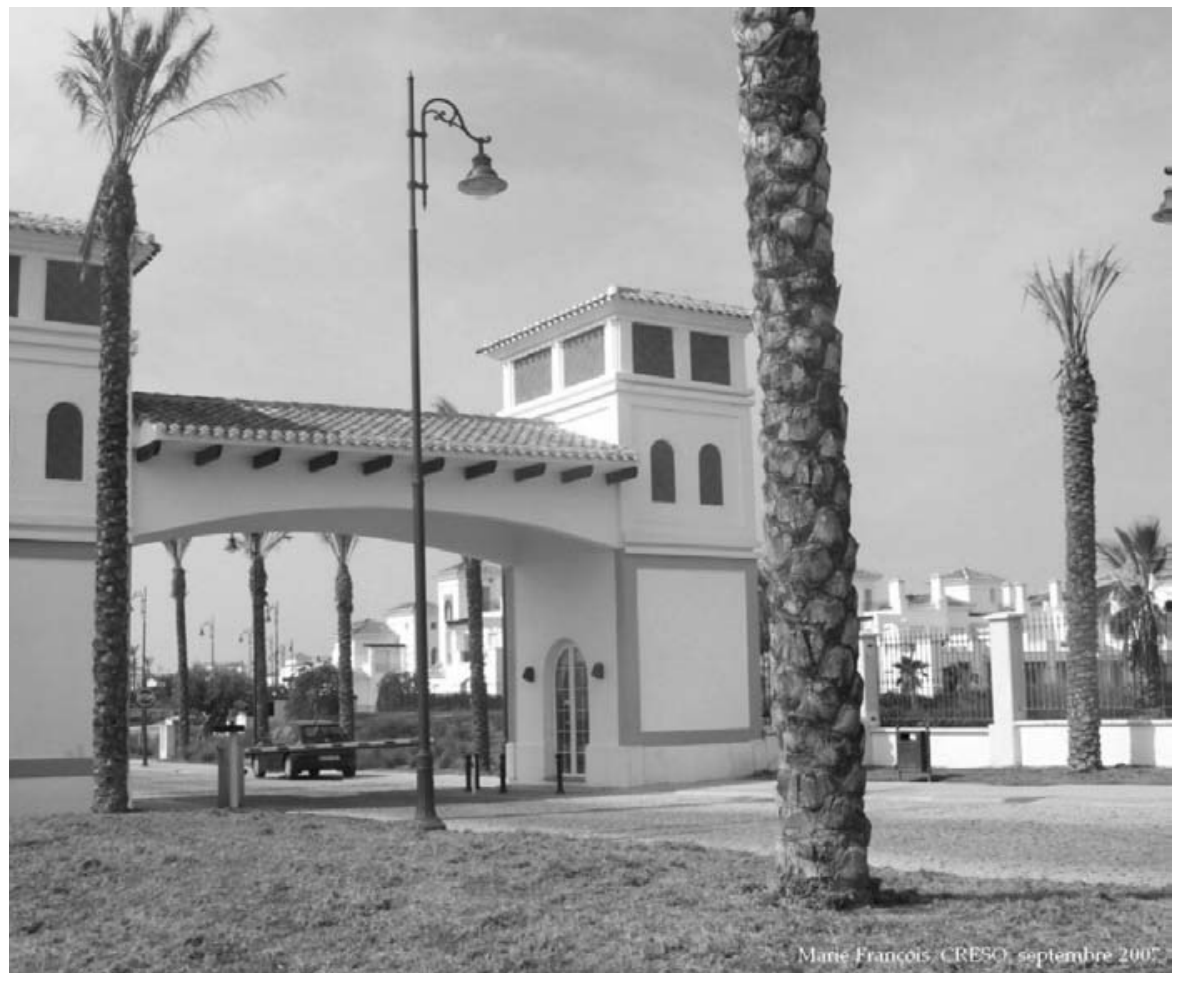




\section{Un desarrollo y un modelo generadores de conflictos}

Voces opuestas a este modelo de desarrollo, a la política y al «nacionalismo hidráulico ${ }^{14}$ del gobierno regional se hacen oír. Aunque en los medios de comunicación los artículos en oposición a esta política regional son poco frecuentes, algunos son reveladores de un cambio de la mentalidad de una parte de la sociedad civil murciana. Según Antonio Campillo, Presidente del Foro Ciudadano de la Región de Murcia y profesor de Filosofía de la Universidad de Murcia, el «Partido Popular creó un mito político, un "nacionalismo hidráulico" y una identidad particular creada, la del agua, en torno al tema «el agua para todos». El PP, en sus propios intereses, creó un «sentimiento patriótico murciano». Este «nacionalismo hidráulico le permitió eludir su responsabilidad en la gestión del agua, al punto de calificar los que se oponen a su política de anti murcianos, de traidores».

Se caricaturiza y se denuncia la campaña «Agua para todos» del Gobierno regional (Figura 8), el lema se desvía, se destina el agua a los campos golf y al turismo.

Una parte de la población murciana toma conciencia de esta campaña regional y eleva la voz para mostrar su desaprobación:

Yo estoy de acuerdo con «Agua para todos». Es un tema que toca a todos. Sin embargo, esta agua no es para mí, pero finalmente para el desarrollo urbanístico. Pienso que todo eso es una mentira y que «Agua para todo» está para los interés privados (un murciano durante la mesa redonda organizada por Ecologistas en Acción, ANSE, WWF/Adena, Asociación de Vecinos Desarrollo sostenible del Garruchal, Asociación Marina de Cope y Ramonete y Asociación Ciudadana Prolitoral, el 2 de junio de 2005, en la Universidad de Murcia, Campus de La Merced).

Se culpa también a las grandes empresas inmobiliarias. Y el principal responsable es la empresa Polaris World. Los valores locales se defienden contra los políticos, que venden la región a las poblaciones extranjeras, a las que se destinan los complejos urbano-turísticos (Figura 9).

Frente a la urbanización desmesurada y a la multiplicación de los complejos turísticos y residenciales asociados a los campos de golf, se organiza una oposición ciudadana en torno a numerosas plataformas. Estas distintas asociaciones defienden generalmente una zona particular, combaten un proyecto en particular.

${ }^{14}$ Término utilizado por Antonio Campillo, Presidente del Foro Ciudadano de la Región de Murcia, en un artículo aparecido en La Verdad de Murcia el 18 de julio de 2005, titulado «El Nacionalismo hidráulico». El foro ciudadano de la región de Murcia es una asociación civil nacida en febrero de 2001. Tiene por objetivo promover el debate público y la participación ciudadana; proponer soluciones concretas a los problemas políticos, económicos, sociales y culturales de la región; luchar por el respeto de los derechos humanos de las personas que residen en la región; por fin, de colaborar activamente con las organizaciones sociales, políticas y sindicales. 
Figura 8. La caricatura como medio de denuncia

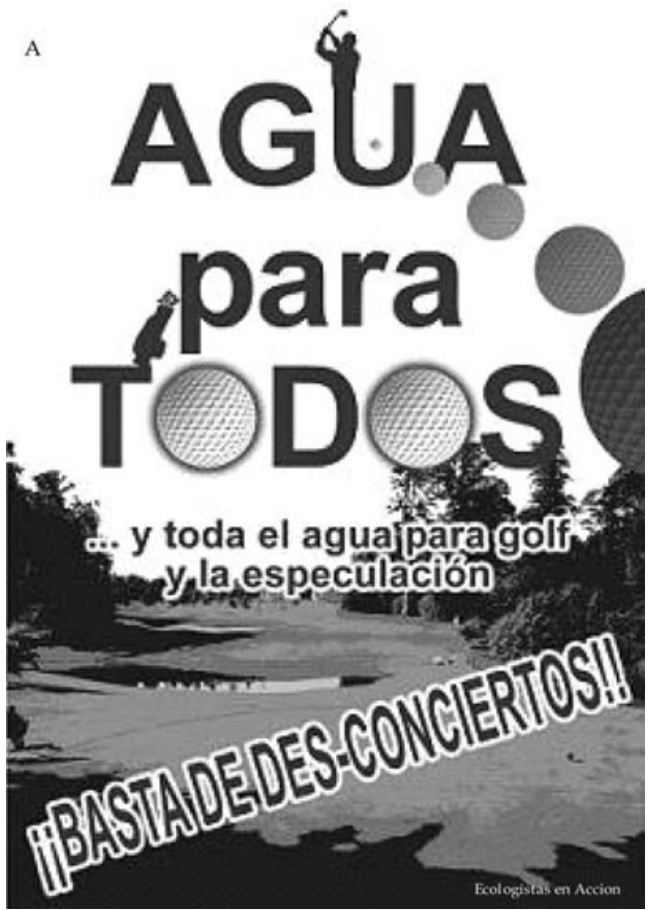

Fuente: www.ecologistasenaccion.org [junio de 2006]

Figura 9. El descontento de las poblaciones locales

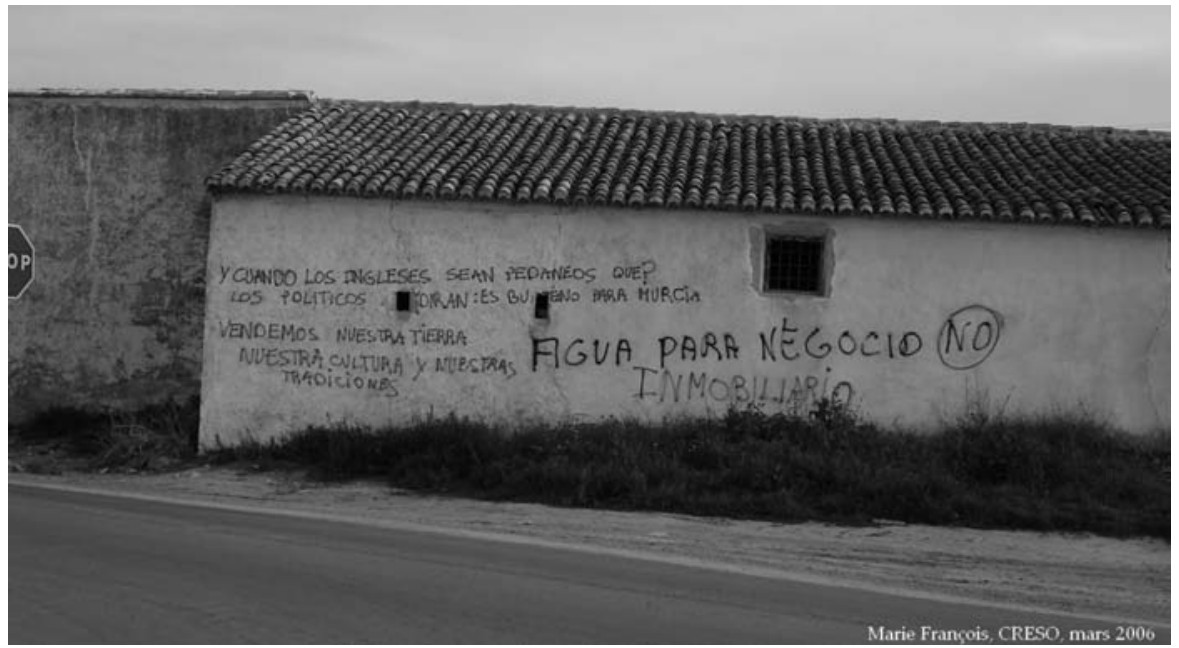


Las poblaciones locales se organizan. Es el caso de la Asociación Marina de Cope-Ramonete (Amacora), que lucha contra el proyecto Puerto deportivo de Cope y también contra la autopista Cartagena-Vera. Según ellos, estos proyectos sirven a los intereses especulativos. Otro caso es la plataforma ciudadana «Alhama no se vende», creada en oposición al resort de Polaris, Condado de Alhama. Estos ciudadanos manifiestan su oposición al proyecto con sus propios medios, a menudo limitados. Una de las acciones más utilizadas es la manifestación y la concentración. Ese fue el caso el 22 de octubre de 2005: un centenar de manifestantes, convocado por la plataforma «Alhama no se vende», se reunió delante de la carpa donde la empresa Polaris World había organizado una reunión de presentación del proyecto Condado de Alhama. Otro ejemplo, el de las tensiones entre la agricultura y la urbanización, es el caso de Valle de Ricote. En Valle de Ricote se lucha contra la desaparición de los sistemas tradicionales, del patrimonio y contra la despoblación (Figura 10).

Figura 10. Valle de Ricote no se vende

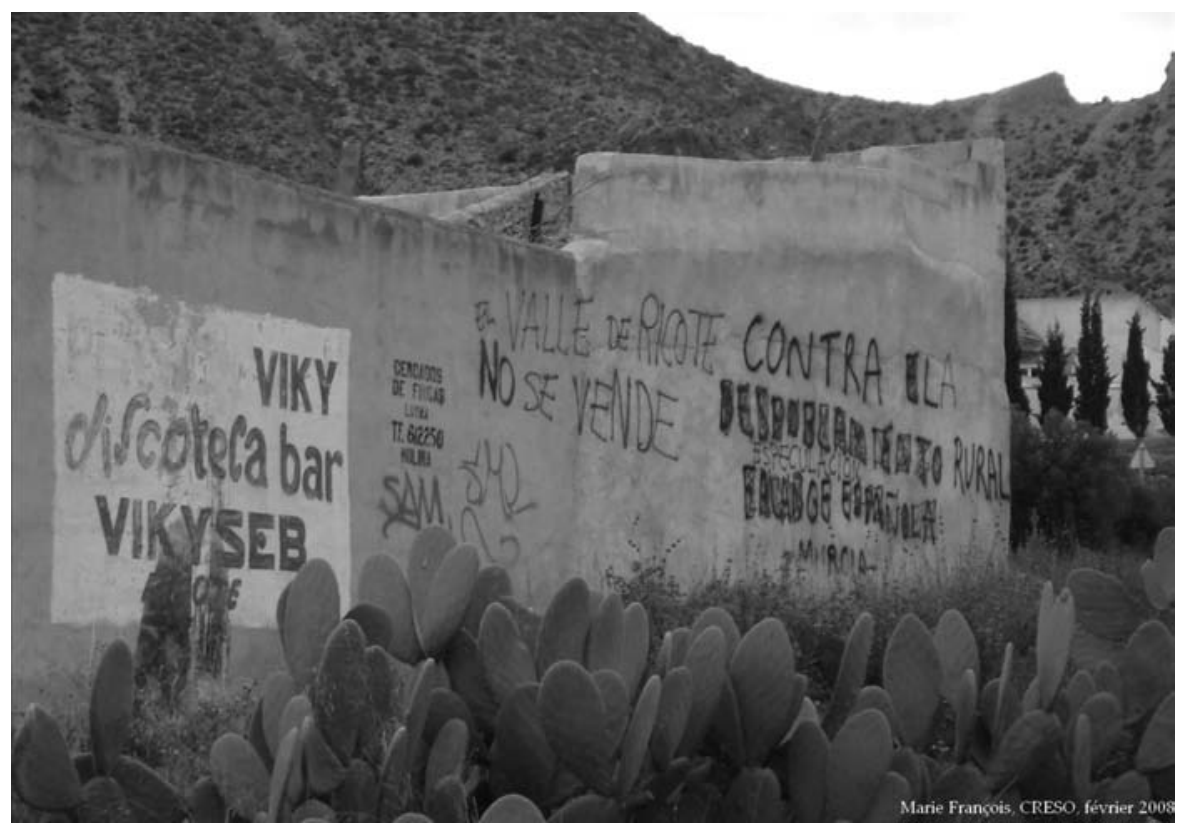

La mayoría de las plataformas locales y asociaciones de vecinos se agrupa en una coordinación regional creada en mayo de 2005, la «Coordinadora Murcia no se vende». Esta Coordinadora lucha contra la degradación del patrimonio natural y cultural y la especulación urbanística. Organiza reuniones, marchas y conferencia-debates para denunciar el modelo urbanístico en curso. Permite hacer converger las luchas y expresarse por unanimidad. 


\section{CONCLUSIONES}

En España, en los años noventa, el más importante cambio de uso del suelo fue la artificialización. Una artificialización vinculada al desarrollo urbano, donde el sector turístico desempeñó un papel preponderante. Las demandas en agua, que hasta ahora se centraban en el sector agrícola, se encuentran modificadas por la urbanización frenética. El agua se reclama para el sector urbano-turístico, que se convierte en motor de desarrollo. El triángulo agua/regadíos/futuro se convierte hoy en agua /turismo/futuro.

El modelo de desarrollo urbano-turístico españoles, en numerosos puntos, insostenible. En este contexto, la Región de Murcia puede considerarse como la caricatura del modelo de desarrollo español de este principio del tercer milenio. Es la Comunidad Autónoma que conoció el tipo de artificialización más fuerte de los suelos durante la última década del siglo XX, proceso que sigue en los años 2000. El Gobierno regional murciano, dirigido por Ramón Luis Valcárcel, del Partido Popular, ha hecho del turismo el pilar de su desarrollo económico futuro. Los resorts, estos complejos residenciales y turísticos sobre el modelo de las Gated Communities, que ocupan grandes superficies y constan de centenares o incluso de millares de viviendas, empujan en todo el territorio murciano. Su producto estrella, el golf, siempre se asocia a una zona residencial y genera el desarrollo de nuevas infraestructuras y zonas residenciales que artificializan el espacio. Por ello, Murcia región tradicionalmente rural y agrícola, conocida bajo el apodo de Huerta de Europa, pasa a ser «resort de Europa donde plantar un ladrillo es más rentable que plantar una lechuga» (Cécile Chambraud, «Les Espagnols construisent au detriment de l'environnement», Le Monde, 10 août 2006).

Esta urbanización turística tiene consecuencias medioambientales y sociales. Consumo excesivo de recursos naturales, destrucción de zonas protegidas, modificación de planes de ordenación para hacer urbanizables centenares o incluso millares de hectáreas, privatización y homogeneización del espacio y de la sociedad son corolarios de este modelo de desarrollo. En los resorts, los residentes se repliegan sobre ellos mismos, viven en autarquía. Por ello, una parte de la población rechaza este modelo reivindicado por el Gobierno regional murciano y se reúne en colectivos coordinados por «Murcia no se vende». Esta parte de la población, que lucha contra la destrucción y la desaparición de la cultura local, así como por el patrimonio natural y cultural, como los que se niegan a unirse a las reivindicaciones del Gobierno regional, son considerados como enemigos, anti murcianos.

Sin embargo, la crisis afectó duramente España y principalmente al sector inmobiliario. Grandes promotores inmobiliarios son insolventes, tal es el caso de la empresa Polaris World: «Polaris World reconoce que quince empresas fi- 
liales, alrededor de la mitad del total de las que integran el grupo, se encuentran en «estado de insolvencia». La deuda de todas ellas se sitúa en torno a los 100 millones de euros» (La Razón, «La crisis arrincona a Polaris World símbolo del «boom del ladrillo», 29 de diciembre de 2009). Y se ven en la obligación de negociar el rescate de su patrimonio por los bancos: «Las entidades implicadas son CAM, Bancaja, Banco Popular y Banco de Valencia y la operación asciende a unos 83 millones de euros. A cambio, Polaris ha puesto en manos de estas entidades una parte del patrimonio que posee en viviendas, campos de golf, suelo y hoteles» (La Verdad de Murcia, «Polaris elude el precipicio», 23 de abril de 2010). Numerosos son los promotores inmobiliarios que liquidan los precios de sus viviendas y terrenos. Signos publicitarios, «ofertas excepcionales», "promociones» jalonan las zonas turísticas. Podemos preguntarnos sobre el futuro de estos proyectos, terrenos y de estos millares de viviendas.

\section{BIBLIOGRAFÍA}

Aledo Tur, A. (2008): «De la tierra al suelo: la transformación del paisaje y el nuevo turismo residencial», Arbor Ciencia, Pensamiento y Cultura. Enero-Febrero de 2008, pp. 99-113.

BurRiel de Orueta, E. (2008): «La "década prodigiosa" del urbanismo español (1997-2006)» en X Coloquio Internacional de Geocrítica Diez años de cambios en el mundo, en la geografía y en las ciencias sociales, 1999-2008. Barcelona, 26 - 30 de mayo de 2008. < http://www.ub.es/geocrit/-xcol/383.htm>. [mayo de 2009].

Consejería de Economía y Hacienda de la Región de Murcia. (2000): Plan estratégico de desarrollo de la Región de Murcia 2000-2006. Murcia. 324 p.

Consejería de Turismo y Cultura de la Región de Murcia. (2001): Diagnóstico turístico de la Región de Murcia. Murcia. diciembre de 2001. 157 p.

Consejería de Turismo y Ordenación del Territorio Región de Murcia. (2004): Directrices y plan de ordenación territorial del litoral de la Región de Murcia. Murcia. $81 \mathrm{p}$.

Consejería de Turismo, Comercio y Consumo. (2005): Turismo en la Región de Murcia 2004. Murcia. 174 p.

Consejería de Turismo, Comercio y Consumo. (2006): Plan Director de turismo de la Región de Murcia 2006-2012. Murcia.

Consejería de Turismo, Comercio y Consumo. (2008): Turismo en la Región de Murcia 2007. Murcia.

Ecologistas en Acción de la Región de Murcia. (2001): La Región de Murcia desprotege espacios naturales para facilitar la expansión urbanística y del regadío. Murcia. 
Ecologistas en Acción de la Región de Murcia. (2006): Presta declaración el Alcalde de Villanueva por la urbanización de La Morra. Murcia, marzo de 2006. 2 p.

El FARO. Valcárcel quiere convertir la Región en un destino familiar en el Reino Unido. 3 de mayo de 2006.

El Faro de Cartagena. José Pablo Ruíz Abellán. Con Marina de Cope podremos competir en oferta con todo el mediterráneo. 12 de julio de 2007.

El Mundo. Marina de Cope, capital del actividad inmobiliaria de Murcia. 6 de mayo de 2005.

Escuela Superior de Arquitectura de Alicante. (2006): Informe Murcia, horizonte prospectivo 2005-2015. Alicante.

Fernández Durán, R. (2006): El tsunami urbanizador español y mundial, Madrid.

Françors, Marie, 2009, Eau et développement en Espagne. Politiques et discours. Les exemples de l'Aragon et de la région de Murcie, Thèse de l'Université de Caen Basse-Normandie et de l'Université de Saragosse (Espagne), sous la direction de Robert Hérin et de Francisco Javier Martinez Gil, 963 p.

Fundación Alternativas. (2007): Urbanismo y democracia - Alternativas para evitar la corrupción. Madrid. 188 p. <http://www.falternativas.org>, [enero de 2009].

GARCíA Marín, R. (2008): «Tensiones socio-ambientales entre ruralidad productiva y otra residencial en la Región de Murcia». XIV Coloquio de Geografía rural. Murcia. pp. 279-293.

Huete Nieves, R. et al. (2008): «¿De qué hablamos cuando hablamos de turismo residencial?», Cuadernos de Turismo, no 22, pp. 101-121.

La Razón. Polaris World y el «nuevo paraíso» de turismo residencial. 12 de diciembre de 2003.

La RAzón. La crisis arrincona a Polaris World símbolo del «boom del ladrillo», 29 de diciembre de 2009.

La Verdad de Murcia. Turismo sin complejos. 24 de julio de 2005.

La Verdad de Murcia. Patología del Resort turístico, Pedro Costa Morata. 10 de febrero de 2006.

La Verdad de Murcia. Valcárcel presenta en Londres el turismo de baja densidad como gran ventaja competitiva frente a otras comunidades. 3 de mayo de 2006.

La Verdad de Murcia. El Ayuntamiento saca adelante el segundo trámite de Marina de Cope con la mayoría absoluta del PP. 29 de diciembre de 2008.

La Verdad de Murcia. El Pleno aprueba el uso residencial de 14 millones de metros de Marina de Cope. 3 de enero de 2009.

La Verdad de Murcia. Polaris elude el precipicio, 23 de abril de 2010.

Martínez Pérez, J-E et al. (2008): Estudio sobre el impacto territorial de los campos de golf y operaciones asociadas en el levante español - Campos de golf y biodiversidad, Alicante. 2008. 94 p. 
NAVARRO Vera J-M et al. (2008a): Estudio sobre el impacto territorial de los campos de golf y operaciones asociadas en el levante español - Estructura territorial. Alicante. $83 \mathrm{p}$.

NAVARRO Vera J-M et al. (2008b): Estudio sobre el impacto territorial de los campos de golf y operaciones asociadas en el levante español - Agua y territorio. Alicante. $121 \mathrm{p}$.

Polaris World. Dossier Corporativo. Murcia. 2006. 19 p.

Polaris World. Condado de Alhama. Murcia. 131 p.

Revista la Economía de la Región de Murcia. La autopista Cartagena-Vera, un eje para el turismo. 6 de agosto de 2006. <laeconomia.com>. [septiembre de 2006].

Revista La Economía de la Región de Murcia. Entrevista de Pedro García Meroño, Presidente de Polaris World. noviembre 2005. <laeconomia.com>. [diciembre de 2005].

SARASA, J-L. (2004): «Incertidumbres en el espacio agrícola y proceso urbanizador «Resort» en la Región de Murcia», Cuadernos de Turismo, n¹4, pp. 7-65. 